\title{
End-user Empowerment: An Interdisciplinary Perspective
}

\author{
Rita Gsenger ${ }^{1}$ \\ Soheil Human ${ }^{1}$ \\ Gustaf Neumann \\ Institute for Information Systems and New Media, \\ Vienna University of Economics and Business (WU Wien), Austria \\ rita.gsenger@wu.ac.at_ $\quad$ soheil.human@wu.ac.at $\quad$ gustaf.neumann@wu.ac.at
}

\begin{abstract}
In virtue of fast spreading emerging technologies, considering end-user empowerment (or human empowerment) while developing or adapting technologies gains importance. Even though many different approaches to end-user empowerment have been proposed, it is hardly clear what "end-user (human) empowerment" is and how it is possible to develop "end-user empowering systems". This paper offers an interdisciplinary perspective on how it can be possible to arrive at a synthesized concept of end-user empowerment, in particular regarding the development of Information and Communication Technologies (ICTs). The provided interdisciplinary perspective includes concepts from Computer Science, Information Systems, Cognitive Science, Psychology, Sociology, Science-Technology-Society, Design, System Science and Philosophy. Based on an interdisciplinary literature review, and from an enactivist, pluralist, and constructivist perspective, we argue that the individual end-users and their needs and values, as well as the environment (including socioeconomical contexts, other actors, etc.) and technologies they interact with, continuously co-create the conception of end-user empowerment. Moreover, we propose that perceiving technological development as co-creation, and considering technologies as value-bearers could provide the first steps in the development of conceptual frameworks required for the development of end-user empowering systems.
\end{abstract}

\section{Introduction}

Our societies are undergoing many digital transformations and various technological devices are an integrated part in many peoples' lives. In 2017, more than 80 percent of individuals in the European Union used the Internet on a daily basis. The ubiquitous

\footnotetext{
${ }^{1}$ These authors contributed equally to this work.
}

presence of ICTs and personal devices, such as PCs, laptops, smartphones, and tablets enabled the rise of digital services, social media and other networks. Additionally, they made the availability of information at any time and in any place possible [1].

Despite the advances that provide many novel useful services, there are issues that need to be addressed. Various new challenges and responsibilities regarding the use of different Information and Communication Technologies (ICTs) can be observed [2]. The acquisition of personal data, for instance, could be used not only for providing personalized services, but also to the detriment of the user; for iexample by insurance companies to determine premiums [3] or by selling sensitive personal data on the market [4]. Another potential issue is the surveillance of user behavior in order to make profit [5]. In addition, cyber-attacks could pose a threat, for example for wearable technologies, which are particularly vulnerable [6] as well as for Social Media applications [7]. The Cambridge Analytica scandal could be an example of the potential sociopolitical consequences of these vulnerabilities [8].

While new regulations such as the European General Data Protection Regulation (GDPR) have tried to protect people's digital rights and create more transparency, the responsibility for the consequences of the users' behavior is oftentimes still passed on to the individuals. In 2017, more than 70 percent of individuals reportedly gave away personal information on the Internet. Consequently, it can be assumed that many end-users do not know the extent of their responsibilities online and which information they are giving away [9] [10]. Potential solutions for these problems could be a more effective policy regulation (like the GDPR) on the one hand [11, 12, [13] and the education of end-users on the other [14]. In addition, various technical and conceptual approaches that could lead to the development of end-user empowering technologies might provide solutions (e.g. [15]).

However, empowerment is a multifaceted and complex concept, used and studied in various disciplines 
like psychology [16, 17, 18, 19], social sciences [20, 21] and media studies [22, 23]. Therefore, differing ways to achieve empowerment, including environmental aspects in which empowerment might have to be conceptualized, are suggested.

The widespread use of ICTs and the crucial role they play in peoples' professional as well as private lives suggest a multitude of relevant contexts for end-user empowerment. In light of the complexity of the issue and the various uses of the notion of end-user empowerment, we argue that it is necessary to provide a good understanding of the concept in order to make the best use of it.

End-user empowerment, however, has been conceptualized from different perspectives. From a social perspective, for example, ensuring access to devices and to knowledge, motivating people and teaching them skills by digital inclusion [24, 21], as well as bridging the digital divide [25] are important aspects of end-user empowerment. Psychological approaches, argue that empowerment is a motivational and active concept [16, 18]. Empowerment by design assumes empowerment in participatory approaches [26], it suggests a redefinition of the relation of humans with technological objects [27, 28] and conceptualizes the different roles end-users and designers can have [29].

The contribution of this paper is an interdisciplinary overview of the understanding and applications of empowerment-related concepts on different levels, providing a step further towards their synthesis. Based on a systematic literature review, we provide an overview regarding the use of end-user empowerment, i.e. "what is end-user (human) empowerment?", categorized into two interconnected levels: 1) social structural empowerment, and 2) individual empowerment. Subsequently, we propose that 1) perceiving the development of empowering technologies (including interconnected phases such as design, implementation, evaluation, application, updating) as co-creation, and 2) considering empowering technologies as value-bearers, can be considered two fundamental elements in the development of conceptual frameworks required for end-user empowering systems, i.e. "how can end-user empowering systems be developed?".

\section{Methodology}

Considering the best practice of systematic literature review (e.g. [30, 31]), the following steps were included in our literature review: (1) Review planning, (2) Review conduction and (3) Review reporting.
The literature was selected in a systematic literature research using the following key words: empowerment, psychological empowerment and design empowerment using scientific online databases (see Table 1). The literature was reviewed in April and May 2019 and grouped according to its relevance for the topic in question. Four types of literature were considered and classified accordingly (see Table 2): (1) Journal Papers, (2) Conference Papers, (3) Anthologies and (4) Monographs.

Table 1. Scientific citation indexing services used.

\begin{tabular}{|l|}
\hline Database name \\
\hline Web of Science - Social Sciences Citation Index \\
\hline IEEE Computer Society Digitai Library \\
\hline Science Direct \\
\hline Vienna University of Economics Library \\
\hline University of Vienna Library \\
\hline
\end{tabular}

Table 2. Document type per relevancy.

\begin{tabular}{|l|l|l|l|l|l|}
\hline Literature & Direct & Indirect & Not-relevant & Total & $\%$ \\
\hline Journal articles & 35 & 19 & 14 & 68 & $43 \%$ \\
$\begin{array}{l}\text { Conference } \\
\text { papers }\end{array}$ & 16 & 11 & 6 & 33 & $21 \%$ \\
Anthologies & 12 & 8 & 9 & 29 & $18 \%$ \\
Monographs & 10 & 9 & 8 & 27 & $17 \%$ \\
Total & 73 & 47 & 37 & 157 & \\
$\%$ & $43 \%$ & $21 \%$ & $18 \%$ & $17 \%$ & \\
\hline
\end{tabular}

Overall, 157 papers, monographs and anthologies were reviewed and included in the table. The literature was categorized according to relevancy regarding the issues discussed and organized in three categories of differing relevance to the topic of empowerment processes:

1. directly relevant, including literature which a) relates to the issues directly regarding the empowerment process in a theoretical sense in different contexts, b) including models of empowerment and c) discusses issues of application of empowerment in development of ICTs.

2. indirectly relevant, including papers which a) refer to examples of the empowerment process in indirectly related contexts and b) discuss issues of application of empowerment models in irrelevant contexts.

3. not relevant, which in most cases discuss specific psychological processes, such as motivation.

Table 2 shows the amount of relevant, indirectly relevant and not relevant literature in detail.

This research aims to investigate human empowerment enabled by the application of technological systems. Literature, classified as indirectly relevant or not relevant was not considered during the detailed investigation of the issue in question. 
As a consequence, 73 papers, monographs and anthologies were considered during the development of the paper.

Table 3 shows the use of the outlined key words in the literature used.

Table 3. Most common keywords.

\begin{tabular}{|l|l|}
\hline Keyword & Occurrence \\
\hline empowerment & 19 \\
psychological empowerment & 11 \\
design & 10 \\
environment & 9 \\
society & 8 \\
model & 6 \\
motivation & 5 \\
\hline
\end{tabular}

During the literature review, the abstracts and introductions were coded, which provided the basis for a categorization of the literature. This classification was updated in the course of a thorough study. Figure 1 shows the conceptual categorization of the studied literature. The categorization includes two main categories which are correlated with our two main background research questions, i.e. 1) "what is human empowerment?", and 2) "how can end-user empowering systems be developed?".

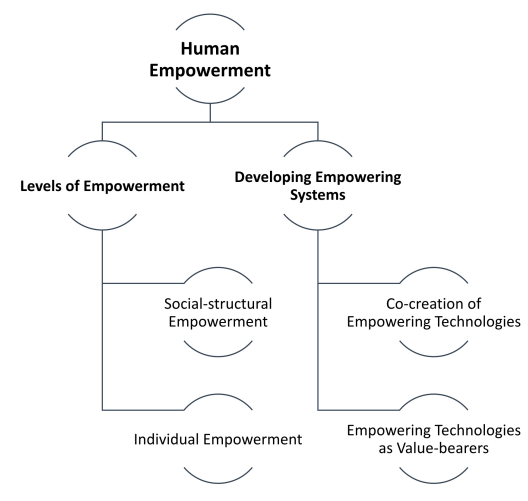

Figure 1. The categorization of concepts covered in relation to human empowerment

\section{Two Interconnected Levels of Empowerment}

Based on the studied literature, conceptualization of end-user empowerment (and empowerment in general) highly depends on the perspective and the level of abstraction. While we do consider the continuous interconnectivity and interaction between different human and non-human actors, two interconnected levels of empowerment can be identified in the literature from a conceptual perspective, i.e. 1) social-structural empowerment, and 2) individual empowerment. In the following, we reflect on each of these levels. Moreover, we will argue that considering empowerment as a continuously emerging property makes it possible to conceptualize the interconnection between different individual and societal processes and contexts involved.

\subsection{Social-structural Empowerment}

The advent and dissemination of the Internet brought with it promises of democratization by making public discourse accessible and participation ubiquitously possible. These predictions are more and more questioned [32, 24]. Furthermore, the uneven social diffusion of ICTs can result in a severe polarisation along social and economic lines in the offline world [33. 34]. Social divides, however, structure the digital world just the same [35].

As a consequence, appropriate legal frameworks and public policies are crucial to ensure equal access to ICTs in order to decrease the reproduction of social exclusion in the digital context [35]. Additionally, the protection of the users' privacy and rights are crucial, for example by giving them control over their personal data [12].

Currently, the Internet not only reproduces societal divides but, at times, also reinforces unequal relations of power and influence. In many cases, the content produced by users on platforms is utilised for the private financial gain of companies, granting few platforms success and leading to a monopolization in the market. Although in many cases users do profit, they are often not included in the financial gains, which stem to some extent from their content and activities on a platform. Advantaged groups in society oftentimes benefit most from the use of ICTs, whereas people with a low income and status, less access and fewer digital skills are disadvantaged [24].

Many platforms, such as mobility service providers, offer cheap or sometimes seemingly free services, giving an impression of community in social networks, economic connections without intermediaries and a new social focus. However, such platforms can construct new unbalanced social structures. While individuals do gain economically from certain offers, some public services are increasingly under pressure [34].

Additionally, inequality can be perceived as a structural problem of the Internet itself. Search engines, for instance, foster centralization, promoting the most visible sites and excluding other content. This content is in turn mainly produced by already economically privileged groups in the offline world [32].

Disadvantaged groups might be even more afflicted if Internet access and digital skills are considered an important prerequisite for employment and civic engagement [36]. As a consequence, the responsibility of getting access to digital technologies on the one hand and the skills to use them on the other hand, which was previously assumed by public and private institutions, 
is shifted to an individual level as the dominant culture becomes increasingly digital. Many services might be only usable by individuals with digital skills and access, whereas other groups would be largely ignored.

In addition to barriers due to skills and knowledge, some users face structural problems of Internet or ICT access due to socio-economical constraints. According to research, disadvantaged groups could be empowered by providing them access to ICTs, including knowledge and skills to use them efficiently. Regarding social media, for example, "empowering people [...] means enhancing the capabilities for genuinely understanding Social Media and their impact on private life" [23]. Additionally, these kinds of technologies could empower their end-users, as they can find financial and other support on social media networks or by "empowering their claims to expertise" [21].

Competences surrounding the use of social media are crucial to enable self-determined judgement and action by end-users. A competent end-user should have knowledge regarding the functions and structures of the media used, for example, to adjust the privacy settings. This knowledge includes the creative use of the media, the capability to assess what kind of interests lie behind the presented phenomena and reflect upon them in a critical manner. Knowledge and evaluation are thus realized in the actions of end-users, enabling the conscious and creative use of the media [14].

Solving digital exclusion solely regarding physical access is not enough [35], however, as the way ICTs are used plays a significant role in bridging the digital divide along socioeconomic lines [37]. Even if the end-user is apt to take care of privacy and security within the technical possibilities of an application and even if the end-user subsequently deletes their data, it seems naive to believe that would suffice, as data controllers store the data of their end-users in multiple locations, in order to be able to provide them reliably [5].

Empowerment could only be guaranteed if power is distributed between all individuals and access to opportunities, skills and knowledge is provided. On a structural level, the conditions for empowerment are considered being crucial. Empowerment could become possible if top down approaches are abandoned for a more participatory system [17]. Consequently, the structures and enablers for empowerment are crucial to make the process possible. In light of social structural inequalities, access to these resources presents an important prerequisite for end-user empowerment, as for example home access to the Internet can provide more possibilities for informal learning.

Skills are required in order to use ICTs and various platforms efficiently. Besides that, attitudes toward the technology, which relate to the motivation and purpose individuals want to use it for and how much they engage are crucial [35]. We would additionally argue that empowerment does not only consist in being able to use technology adequately, but also to have the power and possibility to decline using it [24]. Overall, the social structural level of empowerment refers first to infrastructure as a facilitator of empowerment and second, skills, knowledge and the freedom of choice are crucial to make the process of end-user empowerment sustainable.

\subsection{Individual Empowerment}

Empowerment has been conceptualized in approaches focused on the individual without considering contextual and environmental influences [38], [39]. In the following, we summarize the main notions regarding the individual level of empowerment, focusing on it as an individual psychological and cognitive process embedded in a certain environment. Therefore, interpersonal and reciprocal processes are included. Regarding these, some presuppositions have to be considered:

- Empowerment varies in different people and is considered a progressive development.

- Empowerment takes different forms according to the socioeconomic status, the necessities in people's life situations and their general circumstances.

- Additionally, the requirements for the empowerment process and what form it takes, depend on the context, which is equally subject to change.

- Furthermore, empowerment is fluctuating and changing over time. People can experience different empowering and disempowering processes over time and to different extents.

- Accordingly, a global measure of empowerment would not be productive. It could lead to the assumption of empowerment being a static personality trait instead of a dynamic construct, which would not be accurate for constantly changing individuals in dynamic environments [40].

- To that effect, one single definition would not be appropriate either [38].

Empowerment can be conceptualized as a nomological network focused on control, which is open-ended and 
therefore suitable for different populations and contexts. According to Zimmerman, psychological empowerment is understood as having three components [40]:

1. The intrapersonal component, which involves people's self-conceptions, “domain-specific perceived control and self-efficacy, motivation to control, perceived competence, and mastery". Control, thereby, refers to the perceived ability of influencing different areas in life. This component refers primarily to belief as a prerequisite to try and achieve goals.

2. Empowerment includes a behavioral component, meaning "actions taken to directly influence outcomes".

3. The interactional component of psychological empowerment asserts that people have beliefs about their options in order to reach self set goals and to exert control. Hence it is implied that they are aware of the given norms and values of a community. In that case, the individual needs to know about the resources necessary in order to achieve goals, knowledge on how to obtain them and skills to manage them. Being able to handle resources is referred to as "environmental mastery". Therein, knowledge about causal relations and subsequent effects between people, objects and other factors in the environment, providing a connection between the aspect of perception and the action of control, are included. These skills are crucial for the independence of individuals and for their empowerment.

Empowerment regarding its motivational aspect [18] is picked up by Spreitzer [16], [17], in her discussion on employees in the work context, framed as "intrinsic task motivation" [18]. Motivation is significant insofar as it provides the prerequisites for cognition viewed as pertinent to empowerment. As a consequence, a task should be active and purposeful in order to provide a motivational component. Thomas and Velthouse suggest a model of cognitive empowerment, which consists of a loop between environmental events, task assessment and behaviour: "Environmental events provide data to the individual about the consequences of ongoing task behavior, about conditions and events relevant to future behavior. This data is seen as shaping the individual's task assessments regarding impact, competence, meaningfulness, and choice. These task assessments, in turn, energize and sustain the individual's behavior. This behavior then impacts environmental events [...]" [18].
Regarding the task assessments, Thomas and Velthouse [18] adopt a constructivist view, refuting objectivist stances. Motivation of an individual is considered not only influenced by external events, but also by the manner of the individual's interpretations. They are constituted by "generalized beliefs about impact, competence, meaningfulness, and choice" called "global assessments" [18], which are affected by previous task assessments.

The circle of self-empowerment can be subject to external influences and if either the environmental events or the way of interpreting them is altered, the entire process of empowerment can be enhanced or disturbed. According to the data given, the individual makes assessments along four lines, namely "impact, competence, meaningfulness, and choice" [18]. These have additional effects on motivation, as the individual can conceive them as a reward for a specific task [18]. This concept is reduced to user-empowerment as a "motivational construct manifested in four cognitions" [16]. It includes meaning, competence, self-determination and impact:

- Meaning refers to the decisions an individual makes in reference to their personal values.

- Competence refers to the belief of being able to perform well.

- Self-determination is conceived as autonomous decision-making.

- Impact refers to the influence an individual can have.

If any of these cognitions is not present, the empowerment felt by the individual might be less strong. Thomas and Velthouse [18] conceive it as a continuum, avoiding a dichotomous conception of either being or not being empowered.

Spreitzer [16] additionally mentions the role of the environment shaping empowerment. In her conception, the individual process of interpretation is less emphasized, even as it is focused on the perception of a person presuming an individual role in their work life. On the one hand individuals should believe that they are able to shape their role as they wish and on the other hand they should desire to do so [16].

Besides theoretical reflections, empirical studies developed by Spreitzer (e.g. [16]) indicate that empowerment is continuous and that the four aspects mentioned previously do contribute to an overall feeling of empowerment. Her empirical studies have been conducted cross-culturally and in different work contexts [17]. 
The active conception of empowerment as task motivation is used further by Kim and Gupta [41] to present a conception of end-user empowerment in the context of Information Systems' (IS) usage and design, focusing on the work environment. They propose that perceived fit and job autonomy referring to job design, i.e. "climate for achievement", just like IS design have a positive effect on end-user empowerment. By conducting a study, the authors could find that these aspects have a significant impact on end-user empowerment and they conclude that it has a considerable effect on an end-users behaviour. Additionally, they do imply that emergent use, meaning the innovative use of systems can be achieved directly by means of end-user empowerment [41].

Approaches to empowerment regarding individual control or motivation have been criticized to focus too much on the individual, neglecting the role of community [42], which is to be considered crucial for its very definition [39]. Christens [43] suggests to expand the conception of empowerment as a nomological network with a relational approach. The relational component is influenced by a sense of community on the one hand and influences participation on the other hand. An important element is competence to form relationships with others and subsequently establish solidarity. This is especially important in group settings and regarding collective agency. Additionally, forming interpersonal bonds can help to overcome social divisions and mobilize networks [43].

Interpersonal relationships shape a community and can be instrumental in forming social power [38]. Psychological studies suggest the importance of the connection between community and intrapersonal empowerment ([40], [44], [45], [46]). Speer [38] additionally concludes that a fundamental difference between an intellectual understanding about social change on the one hand, and the individual efficacy and sense of control on the other, can be asserted. That means even though people understand the issues at hand, they may lack the ability to take action [38].

In order to synthesize the individual and the social context, Cattaneo and Chapman [19] propose an Empowerment Process Model. In that context, empowerment is understood as fundamentally connected to the gaining of power in interactions with people and with systems. The authors define empowerment as an "iterative process in which a person who lacks power sets a personally meaningful goal oriented towards increasing power, takes actions toward that goal, and observes and reflects on the impact of this action, drawing on his or her evolving self-efficacy, knowledge, and competence related to the goal". A cyclical process iterates through those six components, which are influenced by the individual's social context. The outcome of the process depends on individual efforts on the one hand and on the respective self-set goals on the other. The social context is crucial, due to the inequalities in people's possibilities of gaining power [19]. This approach highlights the interrelation of the individual level with the social-structural level of empowerment. Overall, individual empowerment is conceived as a continuous process dependent on individual preconceptions, goals and environment. Certain aspects have been identified as crucial for the empowerment process: the possibility to actualize control, the perception of being in control [40], including motivational aspects [18, 16]. Furthermore, intrapersonal aspects and a community is emphasized as influencing the empowerment process [38].

\subsection{Empowerment as a Continuously Emerging Property}

Empowerment in our understanding is a continuously emerging property including multilevel co-creating processes with many dimensions. Figure 2 shows how social-structural and individual empowerment are two crucial dimensions of empowerment. In an enactivist view of the world, the user as a cognitive system is embedded in an environment and inherently connected with it [47, 48]. As a consequence, the individual and the social level are not separate entities, but interdependent processes. Furthermore, the social context and the attributed purpose influence the individual empowerment process. Additionally, the process can vary according to personal differences, experiences and the social environment. The individual, in turn, is more and more capable of influencing the environment during the empowerment process.

\section{Empowering by Design}

Considering the importance of end-user empowerment in our digital age, a question that needs to be addressed is "how can empowering systems be developed?" Our short answer is that empowerment needs to be considered and materialized in systems development, including the interactions they cause, i.e. empowering by design. While proposing a comprehensive guideline regarding the development of empowering systems is beyond the scope of this paper, we reflect in the following on two important aspects that can enable the development of inherently empowering systems. 


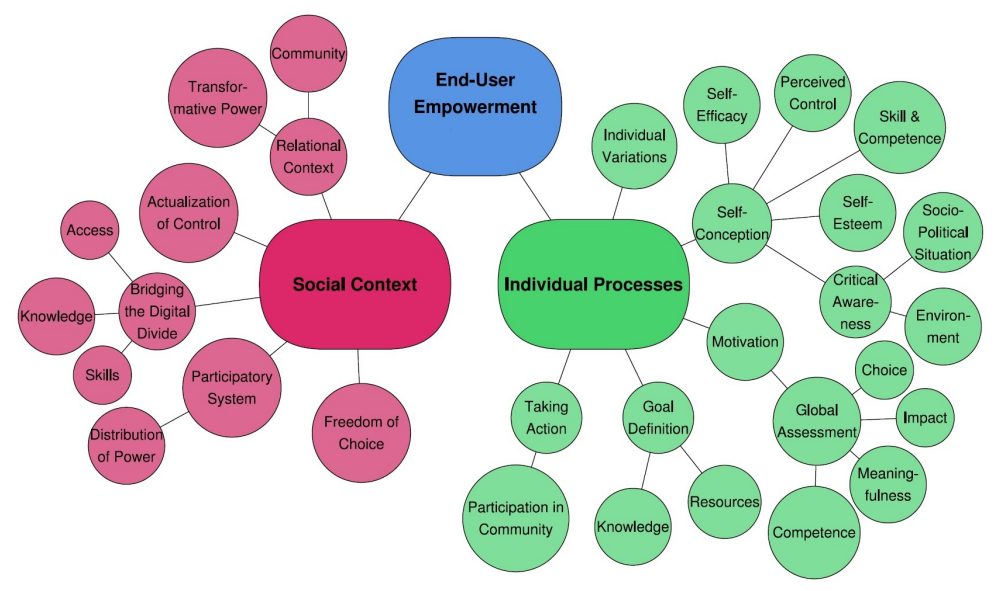

Figure 2. Two Levels of processes and contexts involved in End-User Empowerment

\subsection{Co-creation of Empowering Technologies}

Design of ICTs is argued to enable empowerment, mostly in regard of participatory approaches in the development of a system [49, 29, 26] or arguing that the design of an object is not completed once it is in use [26].

Hippel and Katz [50] suggest toolkits as an alternative to the constant estimation of the end-users' needs, simultaneously enabling them to be innovative and to decide for themselves. While the end-users take care of the tasks related to their needs, the manufacturers provide the solutions and in order for that process to work, toolkits are used [50].

Even though such an account of end-user participation has gained prevalence under "support of market considerations, decision-making legitimacy debates, and cyber-cultural utopias of creative individualism" [29], Vardouli argues that empowerment by design can instead be achieved by means of "technological mediation" [29]. The above mentioned toolkits do not leave many options to the end-users, it is thus doubtful to what extent users can be considered designers in that scenario. The author questions to what extent empowerment can be assigned to an end-user in that context [29].

In the situation of a relation between a designer (or developer), an end-user and a tool the question "who designs?" (or who develops?) is crucial insofar as it can elucidate the relation between the end-user and the technology. Moreover, it can be seen as a crucial part of the question regarding end-user empowerment. The designers (or developer's) role is to provide the environment for this relation. If the question is asked in regards to technological mediation, ethical and political dimensions of the relationship of humans with technology could become relevant, considering the fact that the distinction between producers and consumers becomes more and more unclear [29].

The blurring of boundaries between producer and user could be exemplified by approaches considering the end-user a "produser" [51, 52]. According to Vardouli [29] end-users can subsume different roles in design, as they could be both a rational and a behavioral agent, who is connected to the environment by the designer by means of "fit relations" [29]. The end-user could additionally assume the role of a purely rational agent, making deliberate decisions. Lastly, an end-user could be seen as a behavioural agent, who "forms intentions by conversing with the machine" [29], whereby the designer (or developer) defines the extent of possibilities for the end-user [29].

Co-creation of empowerment technologies is argued to be achievable by means of toolkits and participation by the end-user [50]. Due to the determination of the scope of application by the designer (or developer), participation is argued to be insufficient in order to foster empowerment processes [29]. The latter creates the application with a preconception of values, just like the end-user who has a certain intention by choosing an application and using it in a specific way.

\subsection{Technological Systems as Value-bearers}

Technological systems and devices embody values prevalent in a society. Values are included in the design (and implementation) of systems and their consideration is widely considered a part of the evaluation of a technological device. Therein, not only functional values like efficiency, reliability or user-friendliness are to be considered, but also political and social values. In modern democracies, these might include liberty, justice, enlightenment, privacy, security, friendship, comfort, trust, autonomy, and sustenance [53]. Designers who develop systems with regard to values often have to combine different methodologies 
and various areas of knowledge [53].

Values in the context of design and innovation can refer to four overlapping levels: users, organizations, ecosystems and society. Thereby, the values of the users need to be included in the organization, those of the organization need to be included in the values of the ecosystem and those of the ecosystem in turn need to be aligned with those of society [54]. Moreover, the alignment of values should be a bidirectional process between the overlapping levels.

The values for the users, therein, are presupposing the role of a user as a target audience (or sometimes as a consumer) for the products developed. Therefore, values for the users are considered as making the use of the product a pleasurable experience, in order to keep them using it over an extended period of time. Users preferences and goals, however, differ; meaning the design of a product would need to account for as many of them as possible [54].

From an organization-centric perspective, the creation of values for the organizations themselves, for instance to meet market needs, to make profits and to take care of their employees, is important. A user-centric strategy, however, might have various advantages for an organization as it strives to create value for their customers. That would include anticipating the users needs (and even creating new needs), which subsequently could be met by the organization [54].

A user-centric perspective, if it includes end-user empowerment, would take a different approach. Perceiving empowerment overall as a quest for freedom and emancipation, including the creation of an individuals agency [20], contradicts an account of value creation by creating users' needs. Additionally, it would mean to include the promotion of the ability to decline the use of a certain product, which contradicts the interests of some the organisations, such as profit-oriented companies.

An important aspect of the empowerment process is the setting and pursuing of a meaningful goal. These objectives are additionally influenced by the individual's beliefs and cultural context, as the person would only choose a goal, which was important enough to pursue [19]. In any case, it is still under discussion whether universal cultural values can be assumed [55].

Overall, the design and development of technological systems are influenced by the values of the designers (or developers) on the one hand and the end-users on the other hand. The latter are in turn determined by the goals they pursue and the culture they are embedded in. In that context, emancipation and agency are crucial to consider as part of the empowerment process [20]. All these values need to be materialized in ICTs or in the interactions that the systems would enable. Therefore, we propose perceiving technological systems as value-bearers [56], is an important element of conceptual frameworks aiming to support the development of empowering systems.

\section{Discussion and Future Work}

This paper provides an interdisciplinary overview of different approaches to end-user empowerment. To empower could signify to give or to share power in some sense, like legal power by establishing a framework that can share the power people have on the Internet with legislation. Empowerment can additionally be regarded as a capability to achieve something or to deal with situations adequately, reflected in the capability approaches [23, [14, 20]. Furthermore, it can be understood on an individual level, including the motivation and cognition of a person [18, 17, 16].

In this paper, we have outlined two dimensions being part of empowerment as a continuously emerging property: (1) The social structural dimension, which focuses mainly on capabilities regarding the skills of end-users on the one hand and the access to the technology on the other. (2) The individual dimension, which perceives empowerment as a cognitive process revolving around motivation, control and the actualization of power, including environmental influences [18, 17]. Approaches regarding the design of ICTs for end-user empowerment focus to some extent on participatory accounts, making it possible to give the end-user either more options or a participatory role in the developmental process. The end-user can presume different roles in development, however, which do not necessarily lead to empowerment [29]. In order to conceptualize empowerment as a process in regards to the design and development of ICTs, the values of the designers (or developers) and the end-users should be taken into account. In that regard, agency and emancipatory values should not be overlooked as part of human empowerment [20]. These are crucial for the motivation of an individual, which is in turn is important for the empowerment process [18, 16], as well as the goals individuals would set for themselves [19].

By showing that all of the above mentioned conceptions of empowerment include different aspects in focus and context, we argue that it would be beneficial to synthesize these accounts and include a value-centric and human-centric approach, i.e. empowering by design. We stipulate that an inclusion of a multidimensional account of human empowerment 
would be beneficial for the design and development of accountable systems. Being empowered could enable end-users to use ICTs consciously and in a responsible manner.

Our future work will accordingly focus on the synthesis of various concepts of empowerment, combining them in an interdisciplinary manner and integrating different levels of relevance. Thereby, the individual end-users, the process of empowerment, the external environment and its influence, the technologies in question and the contexts they are embedded in, would be included. Moreover, we would study the relationship between end-user empowerment and emerging concepts such as accountability of Information Systems in more detail. Furthermore, we aim to conduct empirical studies, for instance on the users' perception of empowerment, in order to evaluate different aspects proposed in the literature regarding end-users. Our final goal is to develop an interdisciplinary roadmap towards the development of empowering systems based on the state of the art literature and our empirical findings.

\section{References}

[1] D. Lupton, Digital Sociology. London: Routledge, 2017.

[2] S. Human, G. Neumann, and M. F. Peschl, "[How] Can Pluralist Approaches to Computational Cognitive Modeling of Human Needs and Values Save our Democracies?," Intellectica, vol. 70, pp. 165-180, 2019.

[3] J. Gammack and A. Marrington, "The promise and perils of wearable technologies," in Managing Security Issues and the Hidden Dangers of Wearable Technologies (A. Marrington, D. Kerr, and J. Gammack, eds.), pp. 1-18, Hershey, PA: IGI Global, 2017.

[4] N. Kirchner, S. Human, and G. Neumann, "Context-Sensitivity of Informed Consent: The Emergence of Genetic Data Markets," in Workshop Engineering Accountable Information Systems; European Conference on Information Systems ECIS 2019, (Stockholm, Sweden), 2019.

[5] D. Kerr, K. Butler-Henderson, and T. Sahama, "Security, Privacy, and Ownership Issues with the Use of Wearable Health Technologies," in Managing Security Issues and the Hidden Dangers of Wearable Technologies (A. Marrington, D. Kerr, and J. Gammack, eds.), pp. 161-182, Hershey, PA: IGI Global, 2017.

[6] W. B. Glisson, T. Andel, T. McDonald, M. Jacobs, M. Campbell, and J. Mayr, "Compromising a Medical Mannequin,” pp. 1-11, 2015.

[7] O. Leistert, "Soziale Medien als Technologien der Uberwachung und Kontrolle," in Handbuch Soziale Medien (J.-H. Schmidt and M. Taddicken, eds.), pp. 233-251, Frankfurt am Main: Springer, 2017.

[8] H. Berghel, "Malice Domestic: The Cambridge Analytica Dystopia," Computer, vol. 51, pp. 84-89, May 2018.

[9] L. Brandimarte, A. Acquisti, and G. Loewenstein, "Misplaced Confidences: Privacy and the Control
Paradox," Social Psychological and Personality Science, vol. 4, pp. 340-347, May 2013.

[10] A. P. Felt, E. Ha, S. Egelman, A. Haney, E. Chin, and D. Wagner, "Android permissions: user attention, comprehension, and behavior," in Proceedings of the Eighth Symposium on Usable Privacy and Security SOUPS '12, (Washington, D.C.), ACM Press, 2012.

[11] P. De Hert, V. Papakonstantinou, G. Malgieri, L. Beslay, and I. Sanchez, "The right to data portability in the GDPR: Towards user-centric interoperability of digital services," Computer Law \& Security Review, vol. 34, pp. 193-203, Apr. 2018.

[12] L. Urquhart, N. Sailaja, and D. McAuley, "Realising the right to data portability for the domestic Internet of things," Personal and Ubiquitous Computing, vol. 22, pp. 317-332, Apr. 2018.

[13] S. Wachter, "Normative challenges of identification in the Internet of Things: Privacy, profiling, discrimination, and the GDPR," Computer Law Security Review: The International Journal of Technology Law and Practice, vol. 34, pp. 436-449, June 2018.

[14] U. Wagner, "Kompetenzen fuer soziale Medien," in Handbuch Soziale Medien (J.-H. Schmidt and M. Taddicken, eds.), pp. 251-273, Frankfurt am Main: Springer, 2017.

[15] K. O. Aybar, S. Human, and R. Gsenger, "Digital Inequality: Call for Socio-technical Privacy Management Approaches," in Workshop Engineering Accountable Information Systems; European Conference on Information Systems - ECIS 2019, (Stockholm, Sweden), 2019.

[16] G. Spreitzer, "Psychological Empowerment in the Workplace: Dimensions, Measurement, and Validation," The Academy of Management Journal, vol. 38, pp. 1442-1465, Oct. 1995.

[17] G. Spreitzer, "Taking stock: A review of more than twenty years of research on empowerment at work," in The SAGE Handbook of Organizational Behavior: Volume I. Micro Approaches (J. Barling and C. Cooper, eds.), pp. 54-73, London: Sage Publications, 2008.

[18] K. W. Thomas and B. A. Velthouse, "Cognitive Elements of Empowerment: An "Interpretive" Model of Intrinsic Task Motivation," The Academy of Management Review, vol. 15, pp. 666-681, Oct.

[19] L. B. Cattaneo and A. R. Chapman, "The process of empowerment: A model for use in research and practice.," American Psychologist, vol. 65, no. 7, pp. 646-659, 2010.

[20] C. Welzel, Freedom Rising. Human Empowerment and the Quest for Emancipation. Cambridge: Cambridge University Press, 2013.

[21] L. Rainie and B. Wellmann, Networked. The New Social Operating System. Cambridge: Cambridge University Press, 2012.

[22] Y. Punie, "Introduction: New Media Technologies and end-user Empowerment. Is there a Happy Ending?," in New Media Technologies and User Empowerment (J. Pierson, E. Mante-Meijer, and E. Loos, eds.), pp. 9-27, Frankfurt am Main: Peter Lang, 2011.

[23] E. Mante-Meijer, P. Jo, and E. Loos, "Conclusion: Substantiating User Empowerment," in New Media Technologies and User Empowerment (J. Pierson, E. Mante-Meijer, and E. Loos, eds.), pp. 285-309, Frankfurt am Main: Peter Lang, 2011. 
[24] I. Marien and A. Prodnik, Jernej, "Digital inclusion and user (dis)empowerment: a critical perspective," info, vol. 16, pp. 35-47, Sept. 2014.

[25] M. Peromingo and W. Pieterson, "The new world of work and the need for digital empowerment," Forced Migration Review, vol. 58, pp. 32-33, 2018.

[26] M. Celi and J. Rudkin, "Towards end-user involvement in envisioning practices," in Empowering Users through Design. Interdisciplinary Studies and Combined Approaches for Technological Products and Services (D. Bihanic, ed.), pp. 59-79, Cham: Springer, 2015.

[27] D. Bihanic and P.-D. Huyghe, "Form follows practice," in Empowering Users through Design. Interdisciplinary Studies and Combined Approaches for Technological Products and Services (D. Bihanic, ed.), pp. 1-13, Cham: Springer, 2015.

[28] S. Bianchini, R. Bourganel, and F. Z. E. Quinz, E.and Levillain, "(mis)behavioral objects," in Empowering Users through Design. Interdisciplinary Studies and Combined Approaches for Technological Products and Services (D. Bihanic, ed.), pp. 129-153, Cham: Springer, 2015.

[29] T. Vardouli, "Who designs?," in Empowering Users through Design. Interdisciplinary Studies and Combined Approaches for Technological Products and Services (D. Bihanic, ed.), pp. 13-43, Cham: Springer, 2015.

[30] S. Keele, "Guidelines for performing Systematic Literature Reviews in Software Engineering," tech. rep., EBSE Technical Report EBSE-2007-012007, 2007.

[31] D. Tranfield, D. Denyer, and P. Smart, "Towards a methodology for developing evidence-informed management knowledge by means of systematic review," British Journal of Management, vol. 14, pp. 207-222, Sept. 2003.

[32] M. S. Hindman, The Myth of Digital Democracy. Princeton: Princeton University Press, 2009.

[33] S. Graham, "Bridging Urban Digital Divides? Urban Polarisation and Information and Communications Technologies (ICTs)," Urban Studies, vol. 39, pp. 33-56, Jan. 2002.

[34] J. van Dijck, T. Poell, and M. de Waal, The Platform Society. Oxford: Oxford University Press, 2018.

[35] E. J. Helsper, "A Corresponding Fields Model for the Links Between Social and Digital Exclusion: A Corresponding Fields Model for Digital Exclusion," Communication Theory, vol. 22, pp. 403-426, Nov. 2012.

[36] P. Norris, Digital Divide. Civic Engagement, Information Poverty and the Internet Worldwide. Cambridge: Cambridge University Press, 2001.

[37] C. Harris, L. Straker, and C. Pollock, "A socioeconomic related 'digital divide' exists in how, not if, young people use computers," PLOS ONE, vol. 12, p. e0175011, Mar. 2017.

[38] P. W. Speer, "Intrapersonal and interactional empowerment: Implications for theory," Journal of Community Psychology, vol. 28, pp. 51-61, Jan. 2000.

[39] D. Perkins, "Empowerment," in Political and civic leadership (R. Couto, ed.), pp. 207-218, Thousand Oaks, CA: Sage, 2010.

[40] M. A. Zimmerman, "Psychological empowerment: Issues and illustrations," American Journal of Community Psychology, vol. 23, pp. 581-599, Oct. 1995.
[41] H.-W. Kim and S. Gupta, "A user empowerment approach to information systems infusion," IEEE Transactions on Engineering Management, vol. 61, pp. 656-668, Sept. 2014.

[42] S. Riger, "What's wrong with empowerment," American Journal of Community Psychology, vol. 21, pp. 279-292, June 1993.

[43] B. D. Christens, "Toward Relational Empowerment," American Journal of Community Psychology, vol. 50, pp. 114-128, Sept. 2012.

[44] J. Hughey, N. A. Peterson, J. B. Lowe, and F. Oprescu, "Empowerment and Sense of Community: Clarifying Their Relationship in Community Organizations," Health Education \& Behavior, vol. 35, pp. 651-663, Oct. 2008.

[45] P. W. Speer, C. B. Jackson, and N. A. Peterson, "The Relationship between Social Cohesion and Empowerment: Support and New Implications for Theory," Health Education \& Behavior, vol. 28, pp. 716-732, Dec. 2001.

[46] S. T. Russell, A. Muraco, A. Subramaniam, and C. Laub, "Youth Empowerment and High School Gay-Straight Alliances," Journal of Youth and Adolescence, vol. 38, pp. 891-903, Aug. 2009.

[47] F. Varela, E. Thompson, and E. Rosch, The Embodied Mind: Cognitive Science and Human Experience. Cambridge: MIT Press, 1991.

[48] E. D. Paolo and E. Thompson, "The enactive approach," in The Routledge Handbook of Embodied Cognition (L. Shapiro, ed.), pp. 68-79, London and New York: Routledge, 2014.

[49] R. E. Ladner, "Design for User Empowerment," interactions, vol. 22, pp. 24-29, Feb. 2015.

[50] E. v. Hippel and R. Katz, "Shifting Innovation to end-users via Toolkits," Management Science, vol. 48, pp. 821-833, July 2002

[51] A. Bruns, Blogs, Wikipedia, Second Life, and Beyond. From Production to Produsage. New York: Peter Lang Publishing, 2008.

[52] T.-L. Wang, "From News Receiver to News Produser. The New Relationship between Journalists and Audience in Web 2.0," Advances in Journalism and Communication, vol. 04, no. 02, pp. 55-66, 2016.

[53] M. Flanagan, D. Howe, and H. Nissenbaum, "Embodying Values in Technology. Theory and Practice," in Information Technology and Moral Philosophy (J. van den Hoven and J. Weckert, eds.), pp. 322-354, Cambridge: Cambridge University Press, 2008.

[54] E. den Ouden, Innovation Design. Creating Value for People, Organizations and Society. London: Springer, 2012.

[55] C. Grnloh, "Using technological frames as an analytic tool in value sensitive design," Ethics and Information Technology, pp. 01-05, June 2018.

[56] M. Scheler, Formalism in Ethics and Non-formal Ethics of Values: A New Attempt Toward the Foundation of an Ethical Personalism. Northwestern University Press, 1973. Google-Books-ID: VCDwL_veEugC. 